\title{
Management of invasive Phragmites australis in the Adirondacks: a cautionary tale about prospects of eradication
}

\author{
Brendan Quirion $(\mathbb{D} \cdot$ Zachary Simek $(\mathbb{D} \cdot$ Andrea Dávalos $(\mathbb{D}) \cdot$ Bernd Blossey $(\mathbb{D}$
}

Received: 3 March 2017 / Accepted: 14 July 2017 / Published online: 17 July 2017

(C) The Author(s) 2017. This article is an open access publication

\begin{abstract}
Invasive plant management (largely mechanical and chemical) consumes an ever-increasing portion of budgets for land management organizations, but metrics of success, other than extent of areas treated or resources expended is rarely available. Here we assess success of managing 346 populations of invasive Phragmites australis (range $0.36-4134 \mathrm{~m}^{2}$; cover 37-75\%) in the Adirondack Park in upstate New York, USA. We began by treating 18 patches in 2010 using herbicide; gradually adding patches treated annually or intermittently for a total of 334 by the end of the project period. We monitored each population annually and if $P$. australis was present mapped its spatial extent and estimated cover. We considered
\end{abstract}

The original version of this article was revised due to a retrospective Open Access order.

Electronic supplementary material The online version of this article (doi:10.1007/s10530-017-1513-2) contains supplementary material, which is available to authorized users.

B. Quirion · Z. Simek

The Nature Conservancy, Adirondack Chapter, 8 Nature Way, Keene Valley, NY 12943, USA

A. Dávalos · B. Blossey ( $₫)$

Department of Natural Resources, Cornell University, Ithaca, NY 14853, USA

e-mail: bb22@cornell.edu

\section{A. Dávalos}

Biological Sciences Department, SUNY Cortland,

Cortland, NY 13045, USA
$P$. australis eradicated when live stems were absent from a site for at least three consecutive years. Our treatments reduced size and cover of $P$. australis populations and eradication was achieved at 104 of 294 sites. However, probability of eradicating $P$. australis over a 7-year project timeframe was 0.83 for the smallest patches $\left(0.36 \mathrm{~m}^{2}\right)$, whereas at medium $\left(45 \mathrm{~m}^{2}\right)$ and large patches $\left(>3000 \mathrm{~m}^{2}\right)$ probability of eradication decreased to 0.26 and 0.02 , respectively. Our results question efficacy of managing large $P$. australis populations with the goal of eradication. We urge conservation organizations to clearly articulate management objectives beyond short-term suppression of target plants and to promote accountability by providing quantitative measurements of outcomes.

Keywords Adirondacks · Eradication · Herbicide · Invasive species $\cdot$ Management $\cdot$ Phragmites australis

\section{Introduction}

Conservation and land management organizations spend an ever-increasing amount of their limited resources to manage threats to native biodiversity caused by spread of non-indigenous species (henceforth NIS) (D'Antonio et al. 2004; Pullin et al. 2004; Chornesky et al. 2005; Abella et al. 2015). For example, the 2002 U.S. federal budget for NIS control and related activities was reported at $\$ 777$ million, and 
expenditures have increased to $>\$ 2.2$ billion by 2016 (https://www.doi.gov/invasivespecies/nisc-resources, accessed 16 January 2017). Threats, or at least anticipation of impending impacts, continue to increase with arrival of new NIS (Mills et al. 1994, 2003; van Wilgen et al. 2012; Liebhold et al. 2013; Langor et al. 2014). NIS may negatively impact native species, communities, ecosystem processes such as fire regimes, nutrient cycling, decomposition, pollination, hydrology, food webs, and the ability to manage habitats for declining native species (Mack et al. 2000; Zuefle et al. 2008; Burghardt et al. 2009; Kessler et al. 2011; Powell et al. 2011, 2013; Simberloff 2011; Gaertner et al. 2014; Downey and Richardson 2016).

The ultimate goal of engaging in management of non-indigenous plant species is to either prevent future or reduce current negative impacts. However, deciding which plant species to target for control is difficult, especially when multiple species co-occur and each is associated with or facilitated by other biotic or abiotic stressors (Simberloff and Von Holle 1999; Bertness et al. 2002; Minchinton and Bertness 2003; Nuzzo et al. 2009; Fisichelli et al. 2013; Kuebbing et al. 2013; Dávalos et al. 2014, 2015; Craven et al. 2016). An abundance of prioritization schemes exist, largely developed by scientists, to help land managers make better informed decisions that focus control efforts (Robertson et al. 2003; Fox and Gordon 2009; Downey et al. 2010; Esler et al. 2010b; Darin et al. 2011; Barney et al. 2013; Abella et al. 2015; Adams and Setterfield 2015; Lindenmayer et al. 2015). Depending on a particular scheme's focus, species, habitats, ecosystem services, control strategies, probability of achieving success, expected impacts, and costs may be evaluated. The majority assume that evidence of non-indigenous plant impacts is available and control feasible, yet despite repeated and persistent calls for detailed assessment of impacts (Blossey 1999; Downey 2011, 2014) we lack such information except for a few well-studied systems (Peh 2010; Barney et al. 2013). Furthermore, many management interventions remain un/under evaluated, or results are not readily accessible and managers continue to rely on experience-based learning (Pullin et al. 2004; Foxcroft et al. 2014, and references therein).

For conservation to be successful, decision makers need to know which management actions will be effective or ineffective. Ideally, decisions should be based on effectiveness as demonstrated by scientific experiment, systematic review of evidence (Pullin et al. 2004; van Wilgen et al. 2012), and/or long-term assessment of outcomes (Blossey 1999; Downey 2011, 2014). Targeting a species for control, assumes the target is wholly or partially responsible for undesirable ecosystem change (MacDougall and Turkington 2005). Any successful management should result in decreased negative impacts, declining NIS populations, and a return to more desirable conditions. Yet there is surprisingly little evidence to assess success of invasive plant management beyond superficial metrics of areas treated and resources expended (Reid et al. 2009; Buckley and Han 2014; Foxcroft et al. 2014; Blossey 2016b).

We implemented a 7-year management effort targeting introduced Phragmites australis in the Adirondack Park of New York State using a combination of herbicide treatments. The species is one of the most widespread and successful NIS in North America (Chambers et al. 1999; Kettenring et al. 2012; Saltonstall and Meyerson 2016) and has a long history of management (Marks et al. 1994; Martin and Blossey 2013b; Hazelton et al. 2014). Targeting $P$. australis is usually justified due to its ability to dominate wetland plant communities with widespread anticipated and documented negative impacts on native plant, invertebrate, fish, reptile and bird communities (Benoit and Askins 1999; Able and Hagan 2000; National Research Council 2004; Bolton and Brooks 2010; Kessler et al. 2011; Dibble and Meyerson 2016). The situation in regards to $P$. australis management in the Adirondack Park is unique with extensive forests, clear and limited dispersal corridors, and low human population density that limit disturbance. Hence, we were able to survey and map the large majority of $P$. australis populations in the park interior, resulting in a comprehensive inventory of hundreds of populations. Furthermore, the vast majority of $P$. australis populations are very small, with only a few exceeding $1000 \mathrm{~m}^{2}$, thus limiting impacts the species currently has on local ecosystems. This scenario provided the opportunity to focus on targeting all but a few identified populations while reducing the likelihood of exceeding available resources.

As a result of our treatment and monitoring efforts we expected: (1) P. australis patch area and cover to increase in the absence of herbicide application; (2) $P$. australis patch area and cover to decrease with repeated herbicide application and number of 
treatment years; and (3) to locally eradicate $P$. australis populations with number of eradicated populations increasing as a function of number of years under treatment.

\section{Methods}

Study species

Phragmites australis is a tall, clonal grass able to thrive under a wide range of habitat conditions, from oligohaline tidal wetlands to freshwater wetlands, marshes, ditches, and roadsides, where it produces annual 2-5 $\mathrm{m}$ tall cane like stems. First shoots emerge in early spring and following rhizome growth new stems are added throughout the growing season. Clonal expansion after establishment occurs through an extensive rhizome system producing up to $200 \mathrm{stems} / \mathrm{m}^{2}$ (Haslam 1958). Approximately two thirds of the biomass is allocated to the rhizomesystem that can reach a depth of $2 \mathrm{~m}$ (Haslam 1972). Stems elongate until they reach their final height and produce inflorescences in late summer and early fall. Seed set is variable and not all stems or even populations produce viable seed each year. But in addition to rhizome expansion and fragment transport, seeds, which are dispersed by wind, water, and adhesion to waterfowl throughout the fall and winter, are now recognized as important in dispersal and colonization of new habitats (Baldwin et al. 2010; McCormick et al. 2010; Albert et al. 2015; Galatowitsch et al. 2016; Kettenring et al. 2016).

Present day populations of $P$. australis in North America consist of three different lineages: (1) introduced genotypes overwhelmingly of European origin introduced in the $1800 \mathrm{~s}$ at Atlantic Coast seaports (Saltonstall 2002) that are now widespread throughout North America from southern Canada to the Gulf Coast and southern California (Saltonstall and Meyerson 2016), but absent from Mexico (Colin and Eguiarte 2016); (2) a genetically diverse native and endemic subspecies $P$. australis americanus that is widespread in North America except in the southeastern US but now confirmed in northern Mexico (Colin and Eguiarte 2016; Saltonstall and Meyerson 2016); and (3) a Gulf Coast lineage P. australis berlandieri that occurs throughout the southern US, throughout Mexico, and into South America (Colin and Eguiarte 2016; Saltonstall and Meyerson 2016). Introduced European genotypes have long been considered invasive with widespread detrimental impacts (Marks et al. 1994), while populations of native genotypes are lost (Saltonstall 2002) and are considered of conservation concern in some eastern states. The status of the Gulf Coast lineage as native or introduced remains unresolved (Lambertini et al. 2012; Colin and Eguiarte 2016). Recently the existence of hybrids between European and North American lineages, long suspected due to common garden evidence (Meyerson et al. 2008), has been confirmed in wetlands in New York and Nevada (Saltonstall et al. 2014, 2016).

The ability of introduced $P$. australis to colonize and then dominate wetland plant communities has been variously linked to shoreline development in New England (Bertness et al. 2002; Burdick and Konisky 2003; Silliman and Bertness 2004), prevalence of agriculture and nutrient loading (Kulmatiski et al. 2010; Sciance et al. 2016), salt tolerance (Vasquez et al. 2005), roadside disturbance and dispersal corridors (Jodoin et al. 2008; Brisson et al. 2010), hydrology (Hudon et al. 2005), and superior competitive traits paired with absence of specialized natural enemies (Park and Blossey 2008). This has given rise to research to assess feasibility of biological control for the introduced lineage in North America (Tewksbury et al. 2002a; Blossey 2003; Häfliger et al. 2006a, b; Blossey and Casagrande 2016). Interestingly, there appears to be important biotic resistance to the non-native lineage in less disturbed areas further from human impact (Taddeo and De Blois 2012) and with thriving native plant competitors (Peter and Burdick 2010).

\section{The setting}

The Adirondack Partnership for Regional Invasive Species Management (PRISM), located in Northern New York (NYSDEC 2016), includes the Adirondack Park Forest Preserve (Fig. 1) the largest publicly protected area in the contiguous United States. The region contains over $4060 \mathrm{~km}^{2}$ of protected "forever wild" forest preserve lands with an additional $6000 \mathrm{~km}^{2}$ held in private ownership. Supporting over 100 towns and villages, the Adirondack region is a global conservation model; a place where human communities live side by side and within protected 


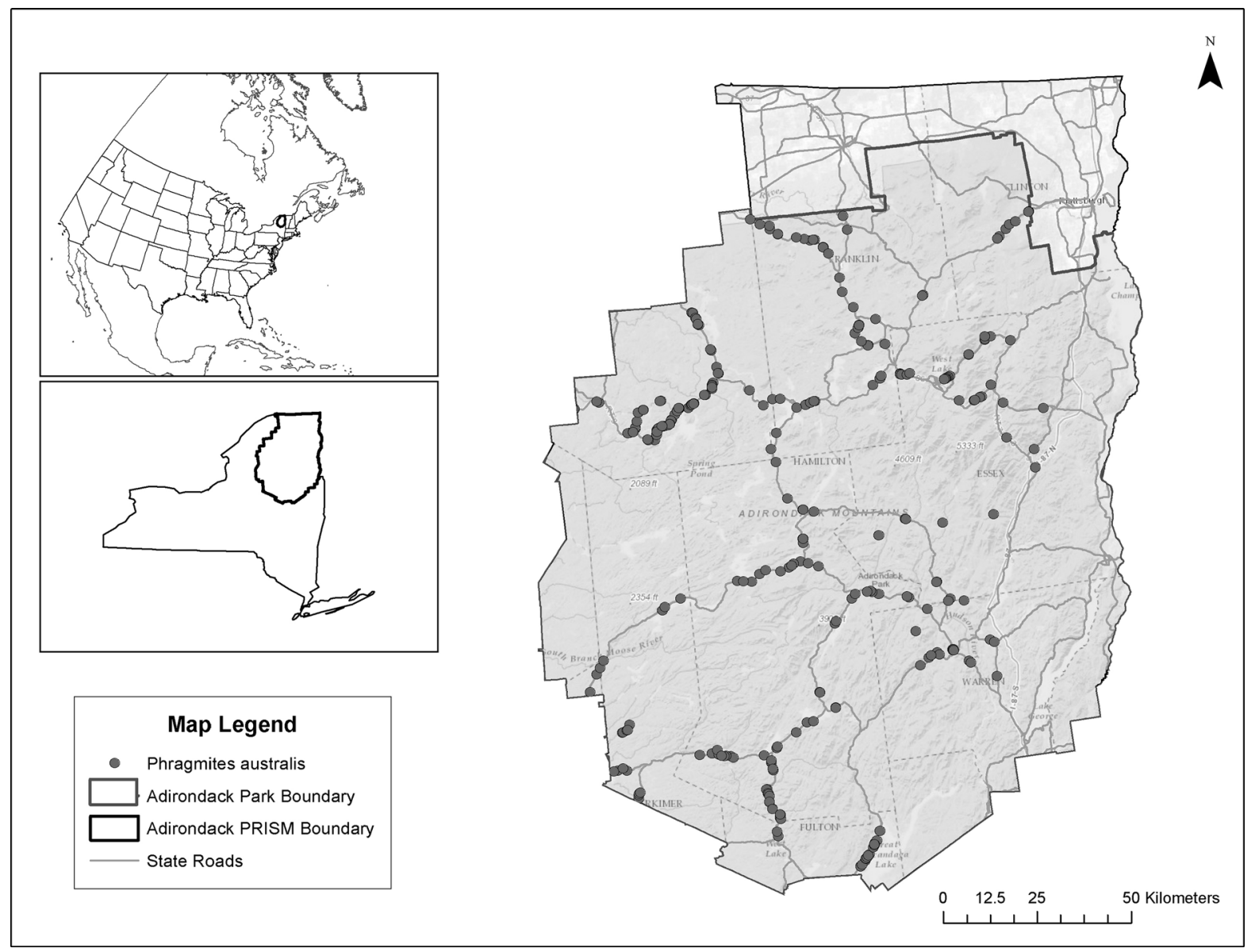

Fig. 1 Documented Phragmites australis locations within the interior Adirondack Park, New York, USA

areas. Over 3000 lakes and ponds, nearly $50,000 \mathrm{~km}$ of rivers and streams, and approximately $2500 \mathrm{~km}^{2}$ of wetlands are contained within the Park's boundary. Elevation varies from near sea level to New York's highest mountain peak, Mount Marcy, at $1628 \mathrm{~m}$. The region supports various ecosystems and habitats including oak-hickory forests, boreal bogs, and, in the higher elevations, alpine zones. These varied habitats sustain a diverse assemblage of plants and animals (Jenkins and Keal 2004).

The Adirondack Park Invasive Plant Program (APIPP) was founded in 1998 and became the first New York PRISM in 2008. Founding partners of APIPP include the New York State Department of Environmental Conservation (NYSDEC), New York State Department of Transportation, Adirondack Park Agency, and the Adirondack Chapter of The Nature Conservancy (TNC). APIPP's mission is to protect the Adirondack region from negative impacts of NIS by coordinating invasive species education and outreach, prevention, surveillance, early detection, rapid response, management, and monitoring efforts. The jurisdictional boundaries of the Adirondack PRISM encompass the $>10,000 \mathrm{~km}^{2}$ landscape of the Adirondack Park as well as the northern portions of Clinton and Franklin Counties (Fig. 1). The program has expanded since its founding and now partners with over 30 different cooperating organizations and hundreds of volunteers representing academic institutions, environmental advocacy groups, lake associations, and other non-governmental organizations. APIPP is funded by New York State's Environmental Protection Fund through contracts with NYSDEC.

APIPP prioritized introduced $P$. australis for management and monitoring in 2010 based on its "very high" New York threat ranking assessment, ability to quickly invade wetland systems, and relatively low distribution and abundance within the Adirondack 
PRISM interior (Jordan and Weldy 2008). The Adirondack region is also home to populations of the native $P$. australis americanus that are in decline due to invasive $P$. australis spread across much of North America (Saltonstall 2002; Perez 2005).

\section{Surveys}

We began documenting and inventorying $P$. australis populations in 2000 using annual roadside surveys due to the species' propensity to spread along roads and subsequently invade adjacent wetlands. At each site, we confirmed species identity as well as invasive versus native status and used a handheld Global Positioning System (GPS, Trimble GeoXT field computers, Waypoint Technology Group, Albany, New York, USA) to collect basic information (date of discovery, coordinates, town and county, and patch size in $\mathrm{m}^{2}$ ). In 2009 we began using TNC's Weed Information Management System (WIMS 3) which allowed collection of additional spatial and treatment data (Buttrick et al. 2007).

We used the WIMS 3 assessment polygon feature to map patch extent by circumnavigating the exterior boundary and including outlier stems to generate patch size $\left(\mathrm{m}^{2}\right)$. The minimum patch size that could be accurately mapped was approximately $0.36 \mathrm{~m}^{2}$, therefore, any smaller patches were automatically mapped as $0.36 \mathrm{~m}^{2}$. We estimated $P$. australis cover $(\%)$ by visual inspection and assigned each site one of five cover classes $(<1,1-10,>10-25,>25-50$, or $>50-100 \%)$. We used the median of the selected cover class to designate patch cover. We used photo documentation to verify that appropriate cover classes were assigned and to document patch size/cover development over time. We repeated size and cover (\%) assessments annually for each site. If we observed no $P$. australis stems upon follow-up assessment, area and cover was recorded as zero.

\section{Herbicide treatments}

We did not obtain sufficient resources or permits to begin comprehensive treatment efforts until 2010. Throughout the study period, and in accordance with variable resources (annual staffing and funding), our survey and treatment efforts fluctuated. Furthermore, varying patch sizes required different treatment approaches to achieve desired effectiveness. We monitored but did not treat 12 populations, which were considered controls throughout the study period.

For smaller patches we first applied herbicide via foliar spray attempting to wet at least $75 \%$ of leaf surface area on both sides of each stem. For larger patches, especially those with high $P$. australis stem densities, we often used a combination of foliar spray and stem injection in the first treatment year. We cut parallel spray access lanes every 1-3 m through the patch and filled or injected each cut $P$. australis stem with herbicide. We also used this technique around intermixed native trees and shrubs to reduce potential non-target effects of foliar spray drift. After treating spray lanes and/or around native vegetation, we applied a foliar spray application to the remainder of the patch. The specific treatment approach deployed on each site was strongly influenced by pre-treatment patch size and stem density, but was performed under each staff member's judgment of predicted treatment efficacy.

All herbicide treatments, regardless of application method, utilized glyphosate-based products with varying percentages of active ingredient (41-53.8\%). We selected products based on their approved use in upland or wetland settings. We incorporated marker dyes into all herbicide applications and added surfactants when performing foliar sprays. Stem injection involved cutting each $P$. australis stem $10-30 \mathrm{~cm}$ above the soil surface and filling the remaining hollow cavities with herbicide solution using a stem injection system (JK1000 Injection System, JK International, LLC, Battle Ground, Washington, USA; for details on herbicide products and adjuvants see Supplementary Table 1).

Over the course of the study period we advanced a site-specific adaptive management approach. The majority of sites required follow-up herbicide treatments as a result of $P$. australis persistence. When resprouts were abundant and in close proximity to each other, we usually continued with foliar spray. Conversely, if resprouts were rare, isolated and/or intermixed with native vegetation we usually used stem injection to reduce likelihood of non-target impacts. In rare circumstances where a single live $P$. australis stem remained we manually removed the plant.

All herbicide treatments took place between 8 July and 6 October of each year. We made every effort to perform our treatments during periods of favorable weather and avoided extreme heat or cold, precipitation, and/or high wind. We also avoided treating 
within two weeks of the first expected fall frost to allow sufficient time for herbicide to translocate to below ground tissues. Although larger sites usually required multiple days of herbicide application, we made every attempt to treat each individual site, with any remaining $P$. australis stems therein, in its entirety once each year. Over the course of the project period only 33 sites did not receive treatment in any given year due to logistical challenges or resource constraints.

Each spring, we cut down or removed dead, standing $P$. australis stems at previously treated sites using brush cutters (STIHL Incorporated, Virginia Beach, Virginia, US) or hand loppers to open the canopy, expedite native plant recovery and facilitate detection of $P$. australis re-sprouts.

\section{Statistical analyses}

We fitted linear mixed models to evaluate effect of years of treatment (or years monitored for untreated sites), pre-treatment area (or initial area for untreated sites), treatment continuity (annual or intermittently), disturbance regime (human or non-human), and site geographical location on $P$. australis patch area $\left(\mathrm{m}^{2}\right)$ and cover (\%). We used polynomial contrasts to evaluate effect of treatment years. We conducted separate analyses for foliar spray and for combined application (foliar plus injection) due to the fact that sites targeted for each method differed in initial average size. We make no inferences about success of different treatment methods since our work and analyses were not designed to assess efficacy of different herbicide application methods. To satisfy model assumptions we log-transformed patch area and arcsine square-root transformed cover. All models included random intercept effects (site effects) and random slope effects (year effects per site). To evaluate significance of explanatory factors, we started with a full model and then compared it with a model without the tested factor via log likelihood tests. We checked assumptions of all models at each step of the model procedure. We fitted all mixed models with package lme4 (Bates et al. 2014) in statistical package R (R Core Team 2016).

For untreated sites, we applied a Cumulative Link Mixed Model to evaluate the effects of initial area and years monitored on $P$. australis cover. We inputted cover as a categorical response (low: $<18 \%$; medium:
18.1-74.9\%; and high: $>74.9 \%$ ) and fitted models using the clmm command in package ordinal (Christensen 2015).

We evaluated probability of $P$. australis relapse and eradication with separate generalized linear models with binomial errors. Relapse models evaluated effects of number of consecutive years of absence and pre-treatment area. Eradication models evaluated effects of pre-treatment area and number of treatment years only. We did not evaluate treatment methods to avoid confounding patch size with treatment approach. We defined eradication as a minimum of 3 years of continuous $P$. australis absence (Rejmánek and Pitcairn 2002). Therefore, only sites managed for more than 3 years were included in this analysis.

\section{Results}

Change in $P$. australis without management

We monitored but did not actively treat $P$. australis at 10 sites and collected pre-treatment data at an additional 114 sites over a 3-6 year period (2009-2016). This allowed us to assess annual rate of increase in patch area and $P$. australis cover in the absence of active management. Initial patch area ranged from 0.36 to $4314 \mathrm{~m}^{2}$, averaging $422.92 \pm 744.78 \mathrm{~m}^{2}$. Patch area was significantly and positively correlated with initial area and increased with years monitored (Supplementary Table 2). We also found a significant interaction between years monitored and initial area due to the fact that smaller patches showed a greater rate of increase than larger patches (Fig. 2; Supplementary Fig. 1). Phragmites australis percent cover varied across control sites ranging from 38 to $75 \%$ (mean 64\%), but was not correlated with initial patch area and did not change significantly over time. Human disturbance and site geographical location had no significant effect on $P$. australis area or cover.

Change in $P$. australis under management

\section{Foliar application}

We treated 243 sites exclusively with foliar spray over a 7-year period (2010-2016) with an average of 4.5 treatment years per site. Average pre-treatment patch size for these sites was $80.7 \pm 253.2 \mathrm{~m}^{2}$ 


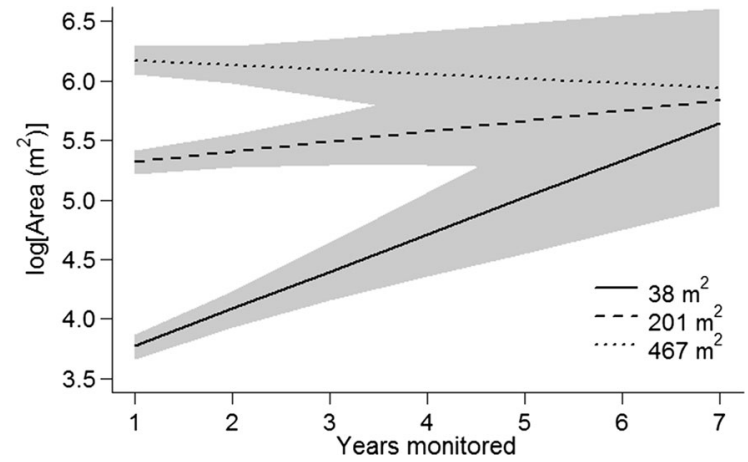

Fig. 2 Phragmites australis patch area ( $\mathrm{m}^{2}$, log-transformed) at sites not treated with herbicide $(\mathrm{N}=124)$ as a function of years monitored and initial patch area. Initial patch areas (38, 201 and $467 \mathrm{~m}^{2}$ ) correspond to $1 \mathrm{st}$, 2nd and 3rd quartiles. Lines depict model predictions and the grey area represents $95 \%$ CI according to linear mixed model effects. For model results see Supplementary Table 2

(means $\pm 1 \mathrm{SD}$, range $0.36-3574.6 \mathrm{~m}^{2}$ ). We treated the majority of these small sites intermittently $(\mathrm{N}=205)$, often because $P$. australis was absent in a given year ( $\mathrm{N}=187$ sites) or because resourcing levels or permitting limitations prevented management $(\mathrm{N}=18$ sites $)$.

Size of $P$. australis patches after 1-7 years of treatment was positively correlated with pre-treatment area, significantly decreased with number of years managed (polynomial effect), and decreased at a faster rate at sites treated intermittently than at sites treated annually (Fig. 3; Supplementary Table 3). We found significant interactions between number of treatment years and initial area and between treatment continuity and number of treatment years (Supplementary Table 3). Percent cover of $P$. australis was positively correlated with pre-treatment patch size and decreased with years of treatment (polynomial effect; Fig. 3). Cover of $P$. australis was significantly higher at sites treated annually than at sites treated intermittently, but treatment continuity did not interact with other factors (Supplementary Table 3). Human disturbance and site geographical location had no significant effect on $P$. australis area or cover. A separate analysis excluding sites not visited due to project constraints indicated similar results.

\section{Combined application}

We treated 91 sites with a combined application of foliar spray and stem injection (in the same year or over multiple years), with 65 sites treated intermittently and 26 sites treated annually. Average pretreatment patch size was $471.8 \pm 765.8 \mathrm{~m}^{2}$ (means $\pm 1 \mathrm{SD}$; range $0.36-5553 \mathrm{~m}^{2}$ ). We did not perform treatments in a given year at 50 sites when $P$. australis was temporarily absent and at 15 sites due to funding or permit limitations.

Patch size of $P$. australis was positively correlated with pre-treatment area and significantly decreased as the number of treatment years increased (Fig. 4). We found a significant interaction between treatment continuity and number of treatment years (Supplementary Table 4): $P$. australis area decreased at a faster rate for sites treated intermittently. Similarly, $P$. australis cover also decreased with treatment years and was positively correlated with pre-treatment area. However, cover was not significantly affected by treatment continuity (Supplementary Table 4). We found a significant interaction between pre-treatment area and number of years treated (Fig. 4). Human disturbance and site geographical location had no significant effect on $P$. australis area or cover. A separate analysis excluding sites not visited due to project constraints indicated similar results.

\section{Local eradication of $P$. australis}

After herbicide application (foliar or combined) $P$. australis was absent for 1-6 consecutive years at 238 of 332 managed sites. At 62 sites $P$. australis reappeared, after one $(\mathrm{N}=45)$, two $(\mathrm{N}=17)$, or $3-4$ $(\mathrm{N}=8)$ years of absence. At the remaining sites, $P$ australis did not re-appear over the study period $(\mathrm{N}=24)$. The probability of reappearance significantly decreased as number of consecutive years of absence increased, with no re-appearance documented after 4 years of absence (Estimate $=-1.12$; $\mathrm{SE}=0.18, P<0.001$; Fig. 5). This result was not significantly affected by patch pre-treatment area.

We considered a minimum three consecutive years absence as an indicator of successful eradication, and therefore only evaluated eradication success on sites managed $>3$ years $(\mathrm{N}=294)$. Following this criterion, we successfully eradicated $P$. australis at 104 of 294 sites. At remaining sites $(\mathrm{N}=190), P$. australis was absent for $1-2$ years ( $\mathrm{N}=58$ and 50 , respectively) or present throughout the study period $(\mathrm{N}=82)$.

The majority of sites where $P$. australis was eradicated $(\mathrm{N}=88)$ received exclusively foliar spray 


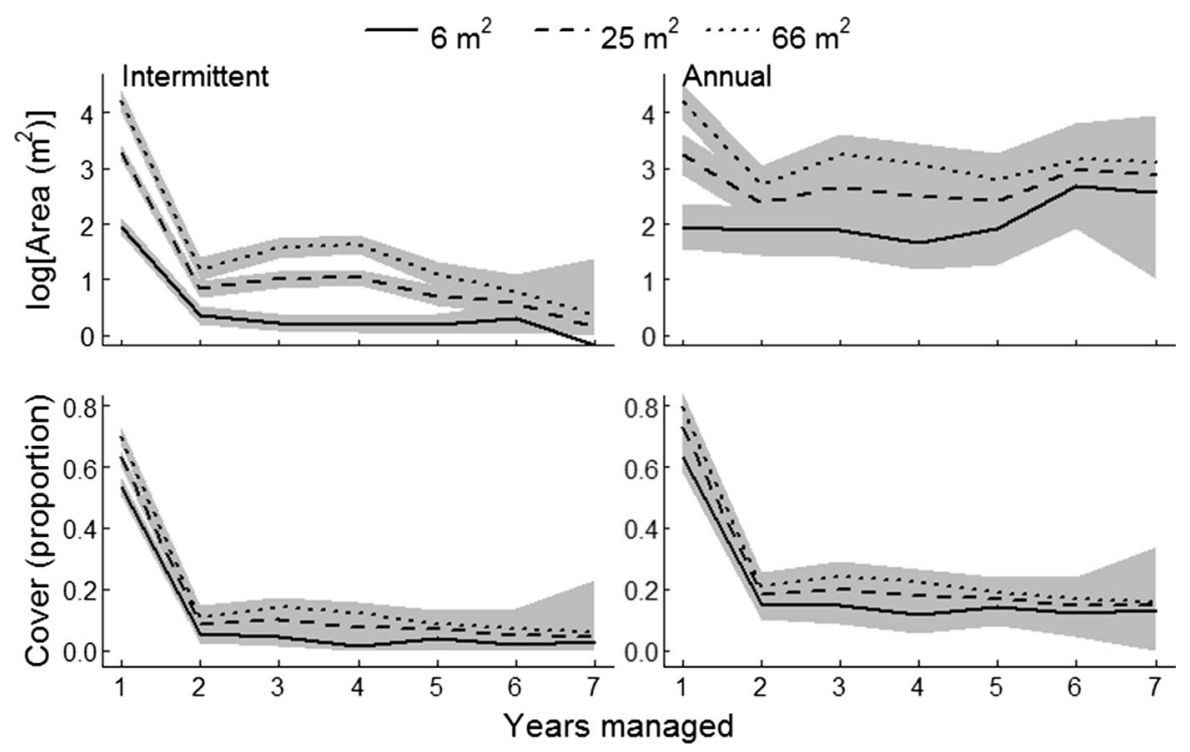

Fig. 3 Phragmites australis patch area $\left(\mathrm{m}^{2}\right.$, log-transformed, top) and cover (\%, arcsine square-root transformed, bottom) as a function of number of years treated and pre-treatment patch area $\left(6,25\right.$ and $\left.66 \mathrm{~m}^{2}\right)$. We treated sites annually (right) or intermittently (left) with foliar spray over a 7-year period
(2009-2016). Pre-treatment patch area corresponds to 1st, 2nd and 3rd quartiles. Lines depict model predictions and the grey area represents $95 \% \mathrm{CI}$ according to linear mixed model effects. For model results see Supplementary Table 3
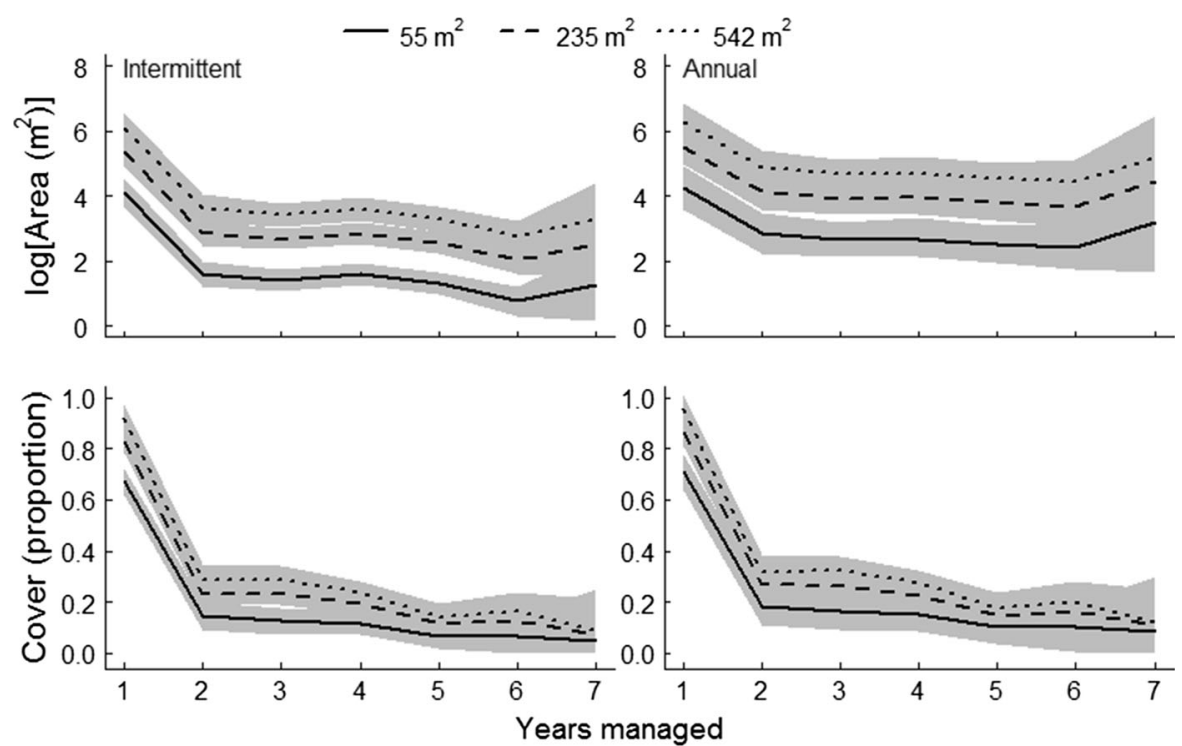

Fig. 4 Phragmites australis patch area $\left(\mathrm{m}^{2}\right.$, log-transformed, top) and cover (\%, arcsine square-root transformed, bottom) as a function of number of years treated and pre-treatment patch area $\left(55,235\right.$ and $\left.542 \mathrm{~m}^{2}\right)$. We treated sites with a combination of foliar spray and stem injection annually (right) or intermittently

(we did not evaluate different herbicide treatments; see Statistical analyses section for details), and all sites were treated intermittently. Average patch size where (left) over a 7-year period (2009-2016). Pre-treatment patch area corresponds to $1 \mathrm{st}, 2$ nd and 3 rd quartiles. Lines depict model predictions and the grey area represents 95\% CI according to linear mixed model effects. For model results see Supplementary Table 4

we were able to successfully eradicate $P$. australis was significantly smaller $\quad\left(28.3 \pm 48 \mathrm{~m}^{2} ; \quad \mathrm{N}=59\right)$ $\left(\mathrm{F}_{1,292}=19.4, P<0.001\right)$ than average patch size 


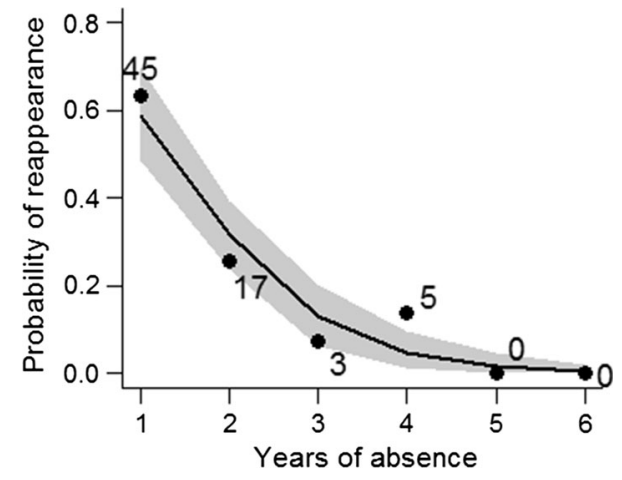

Fig. 5 Probability of $P$. australis reappearance in treated patches as a function of the number of years (1-6) the species was not detected. Lines depict model predictions from a generalized linear model with binomial errors and shaded areas represent $95 \%$ CI based on model predictions from 238 sites where $P$. australis was absent for at least 1 year. Numbers indicate number of sites at which $P$. australis reappeared in a given year

where we failed to eradicate $P$. australis over the 7-year study (309.4 $\left.\pm 649 \mathrm{~m}^{2} ; \mathrm{N}=131\right)$. The probability of eradicating $P$. australis significantly decreased with an increase in pre-treatment area (Estimate $=-0.74 ; \mathrm{SE}=0.1, P<0.001$ ), but was not affected by years of treatment or interaction between both factors (Fig. 6). According to model predictions, probability of eradicating $P$. australis in a 7-year project timeframe at the smallest patches $\left(0.36 \mathrm{~m}^{2}\right)$ is 0.85 , whereas at medium $\left(45 \mathrm{~m}^{2}\right)$ and large patches $\left(>3000 \mathrm{~m}^{2}\right)$ probability of eradicating decreased to 0.3 and 0.02 , respectively. Human disturbance and site geographical location had no significant effect on probability of eradicating $P$. australis.

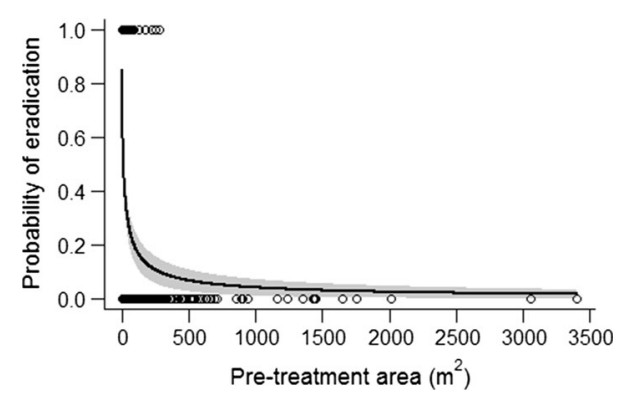

Fig. 6 Probability of $P$. australis eradication according to pretreatment patch size $\left(\mathrm{m}^{2}\right)$. Lines depict model predictions from a generalized linear model with binomial errors and shaded areas represent $95 \%$ CI based on model predictions

\section{Discussion}

Our results of treating invasive $P$. australis in the Adirondacks offer both encouragement and reason for caution for those managing the species. Eradication is clearly a possibility when addressing small infestations and a long-term commitment is made. We were able to eradicate $P$. australis from approximately $35 \%$ of treatment sites and our success is likely to increase substantially (to approx. 72\%) if sites where the species is currently absent for 1-2 years are deemed eradicated in the future. This success was achieved with a financial investment of $<\$ 100,000$. However, extending the monitoring period did not affect our findings regarding patch sizes that can be effectively eradicated. Rapidly responding to new, small populations not only increases the likelihood of eradicating $P$. australis, it also reduces resource requirements and potential future detrimental non-target impacts. This approach is supported by early theoretical models (Moody and Mack 1988), empirical evidence from our study, and other investigations (Taylor and Hastings 2004; Delanoy and Archibold 2007; Simberloff 2009; Buhle et al. 2012).

Conversely, the likelihood for eradicating larger populations drops to 0.1 for those exceeding $300 \mathrm{~m}^{2}$ and to 0.06 for those exceeding $500 \mathrm{~m}^{2}$, indicating that for large populations eradication appears a "pipe dream" (Simberloff 2014). This finding is supported by others (Lombard et al. 2012; Martin and Blossey 2013b) and it is likely that eradication will be even more elusive in areas with high patch connectivity (Chambers et al. 1999; Kulmatiski et al. 2010; McCormick et al. 2010; Kettenring et al. 2012, 2016; Hazelton et al. 2014) or in areas with longer invasion histories. For example, the Michigan Department of Environmental Quality has developed a management prioritization tool (MIDEQ 2014) using multiple ecological, human values, and feasibility criteria where populations covering $<100 \mathrm{~m}^{2}$ are assigned a score of 9 and areas of 4000-80,000 $\mathrm{m}^{2}$ a score of 5, with sites scoring higher receiving priority for management. In the Adirondacks, the largest population we surveyed covered $<4000 \mathrm{~m}^{2}$ and as a result, our management efforts avoided significant impacts and expense associated with managing larger infestations.

While eradication of larger populations was elusive, we were able to greatly reduce $P$. australis patch 
size and particularly cover, with dramatic effects materializing within the first few years of treatment before reductions stabilized. However, incremental reductions continued suggesting that if treatments can be maintained, progress over decades may achieve eradication for these larger, but still comparatively small, sites. We attribute being able to sustain treatments and assessment of outcomes to uninterrupted availability of sufficient resources for the small overall area $P$. australis has invaded in the Adirondacks compared to other regions. The available evidence from across North America suggests that most management agencies are unable to sustain such financially and logistically demanding management strategies once $P$. australis populations are larger and more numerous. The resulting intermittent management and temporary reductions may provide potential short-term ecological benefits, but at enormous longterm expense (Blossey and McCauley 2000; Martin and Blossey 2013b). For example, the Great Lakes Restoration Initiative shows an expenditure of $>\$ 25$ million for $P$. australis management from 2010 to 2015 (https://www.glri.us//) but provides no documentation of outcomes or success beyond expenditures and areas treated (GLRI 2016).

We were surprised by low rates of clonal expansion at sites that did not undergo treatment. Patch expansion rates of $11-46 \%$ for sites that extended over hundreds or even thousands of square meters are reported (Kettenring et al. 2016). In our study only the smallest sites expanded rapidly and we attribute failure of $P$. australis to achieve higher expansion rates to lack of disturbed habitat in the Adirondacks. Except along major roadways, lack of human disturbances is limiting $P$. australis seedling establishment (Byun et al. 2015; Kettenring et al. 2015) and regional encroachment (Bertness et al. 2002; Silliman and Bertness 2004). Large populations may have also reached local limits of available wetland habitat within the forest matrix despite $>240,000$ ha of wetlands in the Adirondacks. We cannot exclude the possibility that biotic resistance by wetland plants (Sakai et al. 2001; Levine et al. 2004; Byun et al. 2013; Zenni and Nuñez 2013), native herbivores (Parker and Hay 2005), or even negative soil feedback (van der Putten et al. 2013) are contributing to reduced local and regional $P$. australis expansion.

Control of NIS is a means to achieve conservation objectives assuming NIS are the driver of or a major contributor to ecosystem deterioration (MacDougall and Turkington 2005) and demise of native species. Evidence from surveys and detailed experiments assessing impacts of invasive $P$. australis is decidedly mixed. Some species are negatively affected such as native wetland plants (Crocker et al. 2017), birds (Benoit and Askins 1999; Whyte et al. 2015), turtles (Bolton and Brooks 2010), and small fish such as Fundulus spp. (Able and Hagan 2000). However, crustaceans (Able and Hagan 2000), Northern pike (Larochelle et al. 2015), certain amphibians, (Cohen et al. 2012; Rogalski and Skelly 2012; Martin and Blossey 2013a; Cohen et al. 2014), and decomposition processes or macroinvertebrate communities (Kennedy et al. 2012) appear to show no negative response to $P$. australis. This conflicting evidence of $P$. australis impacts is sufficient caution to avoid conclusions that reductions in cover and area of patches alone will produce benefits for native biota. We are in the process of assessing outcomes of our herbicide treatments, which appear to have had minimal negative consequences on native plants, with similar diversity and abundance being documented in treatment and adjacent untreated areas (Schwarzberg 2015).

We consider pre- and post-treatment quantitative assessments an essential component of NIS management, especially given increasing evidence that treatments targeting NIS may have local unintended consequences on non-target (Keeley 2006; Kettenring and Adams 2011; Skurski et al. 2013) and even listed species (Baker et al. 2009). In some instances native species of conservation concern did better in the presence of non-indigenous plants when areas remained untreated compared to areas treated with herbicide (Pearson and Callaway 2008; Rinella et al. 2009; Louhaichi et al. 2012; Lazaran et al. 2013). Management of invasive $P$. australis, even when sustained, may not result in the benefits managers are seeking. Collecting, evaluating and publishing quantitative evidence of treatment outcomes is essential.

It has long been a concern to many scientists (Blossey 1999; Downey 2011, 2014) that published evidence on unintended impacts of NIS management, whether biological, mechanical, physical or chemical, is almost entirely absent (Reid et al. 2009; Buckley and Han 2014; Foxcroft et al. 2014; Blossey 2016b) including information on outcomes of $P$. australis management (Hazelton et al. 2014). For example, half 
a million ha of public lands were sprayed with herbicide in the US in 2010 alone to reduce populations of non-indigenous plants with practically no information provided on outcomes (Wagner et al. 2017). Where data exist, assessments are of limited duration (often only a single season) and plot sizes are small, typically $<1 \mathrm{~m}^{2}$. This minimal focus on posttreatment monitoring and restoration is leading to widespread management failures (Kettenring and Adams 2011). We consider sustained and expanded collaborations between land managers and academic scientists a key mechanism for performing these outcome assessments and improving success of NIS management. Advancing these collaborations will require changes in reward systems that currently differ among managers, scientists, funders and the public at large (Acharya 2010; Esler et al. 2010a; Kettenring and Adams 2011; Matzek et al. 2014; Lavoie and Brisson 2015; Matzek et al. 2015; Addison et al. 2016). If not improved, we can expect continuation of systemic failures in how we approach and fund invasive species management for conservation purposes (Stocker 2004; Blossey 2016a, b).

In conclusion, our data suggest that land managers interested in protecting native species and resources under threat from $P$. australis invasion embrace an approach that promotes sustained early detection and rapid response to new, small populations. This may not be feasible in many regions where invasive $P$. australis is well established or rapidly expanding. In these areas, suppression and containment strategies may be warranted, but potential project benefits need to be weighed against significant drawbacks. Management of large $P$. australis populations can divert conservation resources from other projects, have questionable efficacy, and may tax society beyond what will be an acceptable long-term commitment (Martin and Blossey 2013b; Hazelton et al. 2014). At a minimum, outcome assessments of management are essential to evaluate economic and ecological costs and benefits of this approach. Current published evidence, as well as our results, suggest that we lack the ability to eradicate larger $P$. australis populations and that containment and suppression strategies are economically unsustainable and provide limited ecological benefit (Martin and Blossey 2013b). Although opportunities for successful early detection and rapid response exist, promise for successful $P$. australis management as found in the Adirondacks is rare, reinforcing the reality of having to accept larger populations of this NIS (Slobodkin 2001) or to advance biological control (Tewksbury et al. 2002b; Blossey 2003; Martin and Blossey 2013b; Blossey and Casagrande 2016).

Acknowledgements We thank former APIPP Director, Hilary Smith, for securing the resources and funding to implement this project as well as Invasive Plant Control Inc. for providing the seasonal field crews to perform the necessary treatments. We also thank Chris Zimmerman for providing expert guidance on $P$. australis infestation monitoring and A. Dobson for her support with statistical analyses. We appreciate suggestions made by anonymous reviewers that resulted in improvements to the manuscript. We dedicate this paper to the memory of Steven Flint, who initiated and advanced $P$. australis treatments in the Adirondacks until his passing.

Open Access This article is distributed under the terms of the Creative Commons Attribution 4.0 International License (http:// creativecommons.org/licenses/by/4.0/), which permits unrestricted use, distribution, and reproduction in any medium, provided you give appropriate credit to the original author(s) and the source, provide a link to the Creative Commons license, and indicate if changes were made.

\section{References}

Abella SR, Fisichelli NA, Schmid SM, Embrey TM, Hughson DL, Cipra J (2015) Status and management of non-native plant invasion in three of the largest national parks in the United States. Nat Conserv Bulg 10:71-94

Able KW, Hagan SM (2000) Effects of common reed (Phragmites australis) invasion on marsh surface macrofauna: response of fishes and decapod crustaceans. Estuaries 23:633-646

Acharya CB (2010) Forest invasive plant management in the northeastern. US Department of Natural Resources MS. Cornell, Ithaca

Adams VM, Setterfield SA (2015) Optimal dynamic control of invasions: applying a systematic conservation approach. Ecol Appl 25:1131-1141

Addison PFE, Cook CN, Bie Kd (2016) Conservation practitioners' perspectives on decision triggers for evidencebased management. J Appl Ecol 53:1351-1357

Albert A, Brisson J, Belzile F, Turgeon J, Lavoie C (2015) Strategies for a successful plant invasion: the reproduction of Phragmites australis in north-eastern North America. J Ecol 103:1529-1537

Baker WL, Garner J, Lyon P (2009) Effect of imazapic on cheatgrass and native plants in Wyoming big sagebrush restoration for Gunnison sage-grouse. Nat Areas J 29:204-209

Baldwin AH, Kettenring KM, Whigham D (2010) Seed banks of Phragmites australis-dominated brackish wetlands: relationships to seed viability, inundation, and land cover. Aquat Bot 93:163-169 
Barney JN, Tekiela DR, Dollete ESJ, Tomasek BJ (2013) What is the "real" impact of invasive plant species? Front Ecol Environ 11:322-329

Bates D, Maechler M, Bolker B, Walker S (2014) lme4: linear mixed-effects models using Eigen and S4. R package version 1.1-7. http://CRANR-project.org/package=lme4

Benoit LK, Askins RA (1999) Impact of the spread of Phragmites on the distribution of birds in Connecticut tidal marshes. Wetlands 19:194-208

Bertness MD, Ewanchuk PJ, Silliman BR (2002) Anthropogenic modification of New England salt marsh landscapes. Proc Nat Acad Sci USA 99:1395-1398

Blossey B (1999) Before, during, and after: the need for longterm monitoring in invasive plant species management. Biol Invasions 1:301-311

Blossey B (2003) A framework for evaluating potential ecological effects of implementing biological control of Phragmites australis. Estuaries 26:607-617

Blossey B (2016a) The future of biological control: a proposal for fundamental reform. In: Van Driesche R et al (eds) Integrating biological control into conservation practice. Wiley, Chichester, pp 314-328

Blossey B (2016b) Measuring and evaluating ecological outcomes of biological control introductions. In: Van Driesche $\mathrm{R}$ et al (eds) Integrating biological control into conservation practice. Wiley, Chichester, pp 161-188

Blossey B, Casagrande R (2016) Biological control of invasive Phragmites may safeguard native Phragmites and increase wetland conservation values. Biol Invasions 18:2753-2755

Blossey B, McCauley J (2000) A plan for developing biological control of Phragmites australis in North America. Wetl J 12:23-28

Bolton RM, Brooks RJ (2010) Impact of the seasonal invasion of Phragmites australis (common reed) on turtle reproductive success. Chelonian Conserv Biol 9:238-243

Brisson J, de Blois S, Lavoie C (2010) Roadside as invasion pathway for common reed (Phragmites australis). Invasive Plant Sci Manag 3:506-514

Buckley YM, Han Y (2014) Managing the side effects of invasion control. Science 344:975-976

Buhle ER, Feist BE, Hilborn R (2012) Population dynamics and control of invasive Spartina alterniflora: inference and forecasting under uncertainty. Ecol Appl 22:880-893

Burdick D, Konisky RA (2003) Determinants of expansion for Phragmites australis, common reed, in natural and impacted coastal marshes. Estuaries 26:407-416

Burghardt KT, Tallamy DW, Shriver WG (2009) Impact of native plants on bird and butterfly biodiversity in suburban landscapes. Conserv Biol 23:219-224

Buttrick S, Salzer D, Lavine B (2007) Weed information management system v. 3.0. The Nature Conservancy, Portland, Oregon

Byun C, de Blois S, Brisson J (2013) Plant functional group identity and diversity determine biotic resistance to invasion by an exotic grass. J Ecol 101:128-139

Byun C, de Blois S, Brisson J (2015) Interactions between abiotic constraint, propagule pressure, and biotic resistance regulate plant invasion. Oecologia 178:285-296

Chambers RM, Meyerson LA, Saltonstall K (1999) Expansion of Phragmites australis into tidal wetlands of North America. Aquat Bot 64:261-273
Chornesky EA et al (2005) Science priorities for reducing the threat of invasive species to sustainable forestry. Bioscience 55:335-348

Christensen RHB (2015) Ordinal—regression models for ordinal. $\mathrm{R}$ package version. http://www.cran.r-project.org/ package $=$ ordinal/

Cohen JS, Maerz JC, Blossey B (2012) Traits, not origin, explain impacts of plants on larval amphibians. Ecol Appl 22:218-228

Cohen JS, Rainford SKD, Blossey B (2014) Community-weighted mean functional effect traits determine larval amphibian responses to litter mixtures. Oecologia 174:1359-1366

Colin R, Eguiarte LE (2016) Phylogeographic analyses and genetic structure illustrate the complex evolutionary history of Phragmites australis in Mexico. Am J Bot 103:876-887

Craven D et al (2016) The unseen invaders: introduced earthworms as drivers of change in plant communities in North American forests (a meta-analysis). Glob Change Biol. doi: $10.1111 /$ gcb.13446

Crocker E, Nelson EB, Blossey B (2017) Soil conditioning effects of Phragmites australis on native wetland plant seedling survival. Ecol Evol. doi:10.1002/ece3.3024

D'Antonio CM, Jackson NE, Horvitz CC, Hedberg R (2004) Invasive plants in wildland ecosystems: merging the study of invasion processes with management needs. Front Ecol Environ 2:513-521

Darin GMS, Schoenig S, Barney JN, Panetta FD, DiTomaso JM (2011) WHIPPET a novel tool for prioritizing invasive plant populations for regional eradication. J Environ Manag 92:131-139

Dávalos A, Nuzzo V, Blossey B (2014) Demographic responses of rare forest plants to multiple stressors: the role of deer, invasive species and nutrients. J Ecol 102:1222-1233

Dávalos A, Nuzzo V, Blossey B (2015) Interactive effects of deer, earthworms and non-native plants on rare forest plant recruitment. Biodivers Conserv 187:173-181

Delanoy L, Archibold OW (2007) Efficacy of control measures for European buckthorn (Rhamnus cathartica L.) in Saskatchewan. Environ Manag 40:709-718

Dibble KL, Meyerson LA (2016) Detection of decreased quantities of actively spawning female Fundulus heteroclitus in tidally restricted marshes relative to restored and reference sites. Biol Invasions 18:2679-2687

Downey PO (2011) Changing of the guard: moving from a war on weeds to an outcome-oriented weed management system. Plant Prot Q 26:86-91

Downey PO (2014) Protecting biodiversity through strategic alien plant management: an approach for increasing conservation outcomes in protected areas. In: Foxcroft LC, Pysek P, Richardson DM, Genovesi P (eds) Plant invasions in protected areas: patterns, problems and challenges. Springer, Dordrecht, pp 508-528

Downey PO, Richardson DM (2016) Alien plant invasions and native plant extinctions: a six-threshold framework. AoB Plants 8:plw047. doi:10.1093/aobpla/plw047

Downey PO et al (2010) Managing alien plants for biodiversity outcomes-the need for triage. Invasive Plant Sci Manag 3:1-11

Esler KJ, Prozesky H, Sharma GP, McGeoch M (2010a) How wide is the "knowing-doing" gap in invasion biology? Biol Invasions 12:4065-4074 
Esler KJ, van Wilgen BW, Roller KST, Wood AR, van der Merwe JH (2010b) A landscape-scale assessment of the long-term integrated control of an invasive shrub in South Africa. Biol Invasions 12:211-218

Fisichelli NA, Frelich LE, Reich PB, Eisenhauer N (2013) Linking direct and indirect pathways mediating earthworms, deer, and understory composition in Great Lakes forests. Biol Invasions 15:1057-1066

Fox AM, Gordon DR (2009) Approaches for assessing the status of nonnative plants: a comparative analysis. Invasive Plant Sci Manag 2:166-184

Foxcroft LC, Pysek P, Richardson DM, Genovesi P (2014) Plant invasions in protected areas: patterns, problems and challenges. Springer, Dordrecht

Gaertner M, Biggs R, Te Beest M, Hui C, Molofsky J, Richardson DM (2014) Invasive plants as drivers of regime shifts: identifying high-priority invaders that alter feedback relationships. Divers Distrib 20:733-744

Galatowitsch SM, Larson DL, Larson JL (2016) Factors affecting post-control reinvasion by seed of an invasive species, Phragmites australis, in the central Platte River, Nebraska. Biol Invasions 18:2505-2516

GLRI (2016) Great lakes restoration initiative report to congress and the president: fiscal years 2010-2014. https://www. glri.us/pdfs/20160616-glri-report-to-congress-37pp.pdf

Häfliger P, Schwarzlaender M, Blossey B (2006a) Impact of Archanara geminipuncta (Lepidoptera: Noctuidae) on above-ground biomass production of Phragmites australis. Biol Control 38:413-421

Häfliger P, Schwarzländer M, Blossey B (2006b) A comparison of biology and host plant utilization of Archanara geminpuncta, A. dissoluta, A. neurica and Arenostola phragmitidis (Lepidoptera: Noctuidae), potential biological control agents of Phragmites australis (Arundineae: Poaceae). Ann Entomol Soc Am 99:683-696

Haslam SM (1958) Biological flora of the British Isles: Phragmites communis Trin. List Br Vasc Pl 665:585607

Haslam SM (1972) Phragmites communis Trin. (Arundo phragmites L.,? Phragmites australis (Cav.) Trin. ex Steudel). J Ecol 60:585-610

Hazelton ELG, Mozdzer TJ, Burdick DM, Kettenring KM, Whigham DF (2014) Phragmites australis management in the United States: 40 years of methods and outcomes. Aob Plants 6:plu001. doi:10.1093/aobpla/plu1001

Hudon C, Gagnon P, Jean M (2005) Hydrological factors controlling the spread of common reed (Phragmites australis) in the St. Lawrence river (Québec, Canada). Ecoscience 12:347-357

Jenkins J, Keal A (2004) The Adirondack atlas: a geographic portrait of the Adirondack Park. The Wildlife Conservation Society, Bronx

Jodoin Y, Lavoie C, Villeneuve P, Theriault M, Beaulieu J, Belzile F (2008) Highways as corridors and habitats for the invasive common reed Phragmites australis in Quebec, Canada. J Appl Ecol 45:459-466

Jordan MJ, Weldy TW (2008) Invasiveness ranking system for non-native plants of New York. http://www.nyis.info/user_ uploads/a27a2_Phragmites.australis.NYS.pdf

Keeley JE (2006) Fire management impacts on invasive plants in the western United States. Conserv Biol 20:375-384
Kennedy E, Leff LG, de Szalay FA (2012) Herbiciding Phragmites australis: effects on litter decomposition, microbial biomass, and macroinvertebrate communities. Fundam Appl Limnol 180:309-319

Kessler AC, Merchant JW, Allen CR, Shultz SD (2011) Impacts of invasive plants on Sandhill Crane (Grus canadensis) roosting habitat. Invasive Plant Sci Manag 4:369-377

Kettenring KM, Adams CR (2011) Lessons learned from invasive plant control experiments: a systematic review and meta-analysis. J Appl Ecol 48:970-979

Kettenring KM, Blois SD, Hauber DP (2012) Moving from a regional to a continental perspective of Phragmites australis invasion in North America. AoB Plants. doi:10.1093/ aobpla/pls040

Kettenring KM, Whigham DF, Hazelton ELG, Gallagher SK, Weiner HM (2015) Biotic resistance, disturbance, and mode of colonization impact the invasion of a widespread, introduced wetland grass. Ecol Appl 25:466-480

Kettenring KM, Mock KE, Zaman B, McKee M (2016) Life on the edge: reproductive mode and rate of invasive Phragmites australis patch expansion. Biol Invasions 18:2475-2495

Kuebbing SE, Nunez MA, Simberloff D (2013) Current mismatch between research and conservation efforts: the need to study co-occurring invasive plant species. Biol Conserv 160:121-129

Kulmatiski A, Beard KH, Meyerson LA, Gibson JR, Mock KE (2010) Nonnative Phragmites autralis invasion into Utah wetlands. West N Am Nat 70:541-552

Lambertini C et al (2012) Tracing the origin of Gulf Coast Phragmites (Poaceae): a story of long-distance dispersal and hybridization. Am J Bot 99:538-551

Langor DW et al (2014) Non-native species in Canada's boreal zone: diversity, impacts, and risk. Environ Rev 22:372-420

Larochelle M, Dumont P, Lavoie C, Hatin D (2015) Varying effects of common reed invasion on early life history of Northern pike. Trans Am Fish Soc 144:196-210

Lavoie C, Brisson J (2015) Training environmental managers to control invasive plants: acting to close the knowing-doing gap. Invasive Plant Sci Manag 8:430-435

Lazaran MA, Bocetti CI, Whyte RS (2013) Impacts of Phragmites management on marsh wren nesting behavior. Wilson J Ornithol 125:184-187

Levine JM, Adler PB, Yelenik SG (2004) A meta-analysis of biotic resistance to exotic plant invasions. Ecol Let 7:975-989

Liebhold AM, McCullough DG, Blackburn LM, Frankel SJ, Von Holle B, Aukema JE (2013) A highly aggregated geographical distribution of forest pest invasions in the USA. Divers Distrib 19:1208-1216

Lindenmayer DB et al (2015) A long-term experimental case study of the ecological effectiveness and cost effectiveness of invasive plant management in achieving conservation goals: Bitou bush control in Booderee National Park in eastern Australia. PLoS ONE 10:e0128482. doi:10.1371/ journal.pone.0128482

Lombard KB, Tomassi D, Ebersole J (2012) Long-term management of an invasive plant: lessons from seven years of Phragmites australis control. North East Nat 19:181-193

Louhaichi M, Carpinelli MF, Richman LM, Johnson DE (2012) Native forb response to sulfometuron methyl on 
medusahead-invaded rangeland in Eastern Oregon. Rangel J 34:47-53

MacDougall AS, Turkington R (2005) Are invasive species the drivers or passengers of change in degraded ecosystems. Ecology 86:42-55

Mack RN, Simberloff D, Lonsdale WM, Evans H, Clout M, Bazzaz FA (2000) Biotic invasions: causes, epidemiology, global consequences, and control. Ecol Appl 10:689-710

Marks M, Lapin B, Randall JA (1994) Phragmites australis (P. communis): threats, management and monitoring. Nat Areas J 14:285-294

Martin LJ, Blossey B (2013a) Intraspecific variation overrides origin effects in impacts of litter-derived secondary compounds on larval amphibians. Oecologia 173:449-459

Martin LJ, Blossey B (2013b) The runaway weed: costs and failures of Phragmites australis management in the USA. Estuaries Coasts 36:626-632

Matzek V, Covino J, Funk JL, Saunders M (2014) Closing the knowing-doing gap in invasive plant management: accessibility and interdisciplinarity of scientific research. Conserv Lett 7:208-215

Matzek V, Pujalet M, Cresci S (2015) What managers want from invasive species research versus what they get. Conserv Lett 8:33-40

McCormick MK, Kettenring KM, Baron HM, Whigham DF (2010) Spread of invasive Phragmites australis in estuaries with differing degrees of development: genetic patterns, Allee effects and interpretation. J Ecol 98:1369-1378

Meyerson LA, Viola DV, Brown RN (2008) Hybridization of invasive Phragmites australis with a native subspecies in North America. Biol Invasions 12:103-111

MIDEQ (2014) Phragmites treatment/management prioritization tool. http://www.michigan.gov/documents/deq/wrdais-phragtool_423447_7.pdf

Mills EL, Leach JH, Carlton JT, Secor CL (1994) Exotic species and the integrity of the Great Lakes. Bioscience 44:666-676

Mills EL et al (2003) Lake Ontario: food web dynamics in a changing ecosystem (1970-2000). Can J Fish Aquat Sci 60:471-490

Minchinton TE, Bertness MD (2003) Disturbance-mediated competition and the spread of Phragmites australis in a coastal marsh. Ecol Appl 13:1400-1416

Moody ME, Mack RN (1988) Controlling the spread of plant invasions: the importance of nascent foci. J Appl Ecol 25:1009-1021

National Research Council (2004) Endangered and threatened species of the Platte River. National Academies, Washington

Nuzzo VA, Maerz JC, Blossey B (2009) Earthworm invasion as the driving force behind plant invasion and community change in northeastern North American forests. Conserv Biol 23:966-974

NYSDEC (2016) Partnerships for regional invasive species management (PRISM). http://www.dec.ny.gov/animals/ 47433.html. Accessed 2 May 2016

Park MG, Blossey B (2008) Importance of plant traits and herbivory for invasiveness of Phragmites australis (Poaceae). Am J Bot 95:1557-1568

Parker JD, Hay ME (2005) Biotic resistance to plant invasions? Native herbivores prefer non-native plants. Ecol Let 8:959-967
Pearson DE, Callaway RM (2008) Weed-biocontrol insects reduce native-plant recruitment through second-order apparent competition. Ecol Appl 18:1489-1500

Peh KSH (2010) Invasive species in Southeast Asia: the knowledge so far. Biodivers Conserv 19:1083-1099

Perez S (2005) A multi-scale approach to investigating the distribution of the non-native genotype of Phragmites australis found in four watersheds of northern. New York State Department of Natural Resources MS. Cornell University, Ithaca, p 121

Peter CR, Burdick DM (2010) Can plant competition and diversity reduce the growth and survival of exotic Phragmites australis invading a tidal marsh? Estuaries Coasts 33:1225-1236

Powell KI, Chase JM, Knight TM (2011) A synthesis of plant invasion effects on biodiversity across spatial scales. Am J Bot 98:539-548

Powell KI, Chase JM, Knight TM (2013) Invasive plants have scale-dependent effects on diversity by altering speciesarea relationships. Science 339:316-318

Pullin AS, Knight TM, Stone DA, Charman K (2004) Do conservation managers use scientific evidence to support their decision-making? Biol Conserv 119:245-252

Reid AM, Morin L, Downey PO, French K, Virtue JG (2009) Does invasive plant management aid the restoration of natural ecosystems? Biol Conserv 142:2342-2349

Rejmánek M, Pitcairn M (2002) When is eradication of exotic pest plants a realistic goal? In: Veitch CR, Clout MN (eds) Turning the tide: eradication of invasive species. IUCN, SSC Invasive Species Specialist Group, Cambridge, pp 249-253

Rinella MJ, Maxwell BD, Fay PK, Weaver T, Sheley RL (2009) Control effort exacerbates invasive-species problem. Ecol Appl 19:155-162

Robertson MP et al (2003) A proposed prioritization system for the management of invasive alien plants in South Africa. S Afr J Sci 99:37-43

Rogalski MA, Skelly DK (2012) Positive effects of nonnative invasive Phragmites australis on larval bullfrogs. PLoS ONE 7:e44420. doi:10.41371/journal.pone.0044420

Sakai AK et al (2001) The population biology of invasive species. Ann Rev Ecol Syst 32:305-332

Saltonstall K (2002) Cryptic invasion by a non-native genotype of the common reed, Phragmites australis, into North America. Proc Nat Acad Sci USA 99:2445-2449

Saltonstall K, Meyerson LA (2016) Phragmites australis: from genes to ecosystems. Biol Invasions 18:2415-2420

Saltonstall K, Castillo HE, Blossey B (2014) Confirmed field hybridization of native and introduced Phragmites australis (Poaceae) in North America. Am J Bot 101:211-215

Saltonstall K, Lambert AM, Rice N (2016) What happens in Vegas, better stay in Vegas: Phragmites australis hybrids in the Las Vegas Wash. Biol Invasions 18:2463-2474

Schwarzberg E (2015) Native vegetation reestablishment analysis: post treatment surveys of Japanese knotweed and Phragmites australis in the Adirondack Park. A report by Adirondack Research LLC to the Adirondack Park Invasive Plant Program, Keene Valley, New York, USA

Sciance MB, Patrick CJ, Weller DE, Williams MN, McCormick MK, Hazelton ELG (2016) Local and regional disturbances associated with the invasion of Chesapeake Bay marshes 
by the common reed Phragmites australis. Biol Invasions 18:2661-2677

Silliman BR, Bertness MD (2004) Shoreline development drives invasion of Phragmites australis and the loss of plant diversity on New England salt marshes. Conserv Biol 18:1424-1434

Simberloff D (2009) We can eliminate invasions or live with them. Successful management projects. Biol Invasions 11:149-157

Simberloff D (2011) How common are invasion-induced ecosystem impacts? Biol Invasions 13:1255-1268

Simberloff D (2014) Eradication: pipe dream or real option? In: Foxcroft LC, Pysek P, Richardson DM, Genovesi P (eds) Plant invasions in protected areas: patterns, problems and challenges. Springer, Dordrecht, pp 549-560

Simberloff D, Von Holle B (1999) Positive intractions of nonindigenous species: invasional meltdown? Biol Invasions $1: 21-32$

Skurski TC, Maxwell BD, Rew LJ (2013) Ecological tradeoffs in non-native plant management. Biol Conserv 159:292-302

Slobodkin LB (2001) The good, the bad and the reified. Evol Ecol Res 3:1-13

Stocker RK (2004) The management of invasive plants in the United States: Are scientists providing what managers need? Weed Technol 18:1528-1532

Taddeo S, De Blois S (2012) Coexistence of introduced and native common reed (Phragmites australis) in freshwater wetlands. Ecoscience 19:99-105

Taylor CM, Hastings A (2004) Finding optimal control strategies for invasive species: a density-structured model for Spartina alterniflora. J Appl Ecol 41:1049-1057

R Core Team (2016) R: a language and environment for statistical computing. R Foundation for Statistical Computing, Vienna. http://www.R-project.org/
Tewksbury L, Casagrande R, Blossey B, Häfliger P, Schwarzländer M (2002a) Potential for biological control of Phragmites australis in North America. Biol Control 23:191-212

Tewksbury L, Casagrande R, Gassmann A (2002b) Swallowworts. In: van Driesche R, Blossey B, Hoddle M, Lyon S, Reardon R (eds) Biological control of invasive plants in the eastern United States. Forest Health Technology Enterprise Team, Morgantown, pp 209-216

van der Putten WH et al (2013) Plant-soil feedbacks: the past, the present and future challenges. J Ecol 101:265-276

van Wilgen BW et al (2012) An assessment of the effectiveness of a large, national-scale invasive alien plant control strategy in South Africa. Biol Conserv 148:28-38

Vasquez EA, Glenn EP, Brown JJ, Guntenspergen GR, Nelson SG (2005) Salt tolerance underlies the cryptic invasion of North American salt marshes by an introduced haplotype of the common reed Phragmites australis (Poaceae). Mar Ecol Prog Ser 298:1-8

Wagner V, Antunes PM, Irvine M, Nelson CR (2017) Herbicide usage for invasive non-native plant management in wildland areas of North America. J Appl Ecol 54:198-204

Whyte RS, Bocetti CI, Klarer DM (2015) Bird assemblages in Phragmites dominated and non-Phragmites habitats in two Lake Erie coastal marshes. Nat Areas J 35:235-245

Zenni RD, Nuñez MA (2013) The elephant in the room: the role of failed invasions in understanding invasion biology. Oikos 122:801-815

Zuefle ME, Brown WP, Tallamy DW (2008) Effects of nonnative plants on the native insect community of Delaware. Biol Invasions 10:1159-1169 